А.И. ПОВОРОЗНЮК, д-р техн. наук, доц., НТУ "ХПИ", Харьков, $\boldsymbol{A}$.E. ФИЛАТОВ $\boldsymbol{A}$, канд. техн. наук, доц., НТУ "ХПИ", Харьков

\title{
ОПИСАНИЕ ЭТАЛОНА ДЛЯ СИНТЕЗА ФУНКЦИИ ОТКЛИКА НЕЛИНЕЙНОГО ФИЛЬТРА В ЗАДАЧЕ СТРУКТУРНОЙ ИДЕНТИФИКАЦИЯ БИОМЕДИЦИНСКИХ СИГНАЛОВ С ЛОКАЛЬНО СОСРЕДОТОЧЕННЫМИ ПРИЗНАКАМИ
}

В работе рассматривается задача структурной идентификации биомедицинских сигналов с локально сосредоточенными признаками с помощью цифрового нелинейного фильтра, а также способы описания эталона искомого класса структурных элементов на основе моделей полезного сигнала для синтеза функции отклика проектируемого фильтра. Ил.: 2. Библиогр.: 10 назв.

Ключевые слова: структурная идентификация, биомедицинский сигнал, локально сосредоточенные признаки, цифровой нелинейный фильтр, эталон, структурный элемент.

Постановка проблемы. Создание новых информационных технологий оценки состояния сердца и сердечно-сосудистой системы при проектировании интеллектуальных компьютерных кардиологических систем поддержки принятия решений (ИККСППР) является актуальной научно-технической проблемой. При проектировании ИККСППР можно выделить следующие основные этапы обработки биомедицинских сигналов (БМС) с локально сосредоточенными признаками (ЛСП): регистрация и оцифровка сигнала; предварительная обработка сигнала; структурная идентификация (СИ) сигнала; расчет диагностических показателей; синтез решающих правил; постановка диагноза [1]. Рассматриваемые БМС с ЛСП являются квазипериодическими сигналами, имеющими сложную форму и несущие информацию о состоянии объекта на небольших фрагментах интервала наблюдения сигнала. Одним из ответственных и трудно формализуемых этапов обработки БМС является этап СИ, который заключается в выделении на фоне помех информативных фрагментов сигнала, называемых структурными элементами (СЭ). Повышение эффективности методов СИ является актуальной задачей при проектировании ИККСППР.

Анализ литературы. Задачу структурной идентификации БМС с ЛСП можно рассматривать как локальную цифровую обработку сигнала скользящим окном или апертурой, что по определению является цифровой фильтрацией [2 - 4]. При этом размер окна выбирается намного меньше длины обрабатываемого сигнала, и для каждого 
положения окна выполняются однотипные действия, которые определяют так называемый отклик или выход фильтра. Т.к. обычно действия, определяющие отклик фильтра, не изменяются в процессе перемещения по сигналу и описываются нелинейными функциями, то СИ выполняется с помощью стационарного нелинейного фильтра (НФ).

Целью цифровой фильтрации БМС с ЛСП является обнаружение СЭ заданного вида, а также их локализация на рассматриваемом сигнале. Задача обнаружения сигнала широко рассмотрена в радиолокации [5]. При этом на основании параметров сигнала для обнаружения проектируются соответствующие фильтры, например, согласованные фильтры, целью применения которых является вычисление некоторого показателя. Анализ показателя с помощью порогового правила дает возможность решить, действительно ли присутствует нужный сигнал во входной смеси сигнала с шумом. Эти идеи были положены в основу синтеза НФ для решения задачи структурной идентификации БМС с ЛСП. Для построения НФ были рассмотрены различные модели полезного сигнала (МПС), анализ которых приведен в [6 - 8]. В модели МПС-1 БМС может быть описан в виде решетчатой функции времени. Это наиболее простая модель, в которой не учитываются особенности БМС с ЛСП. Модель МПС-2 - это модель разложения БМС по базисным функциям. В МПС-2 могут использоваться, например, ряды Фурье или вейвлеты. В модели МПС-3 БМС представлен в виде функции, кусочнозаданной на периоде последовательностью фрагментов. При этом на каждом временном отрезке задается своя аппроксимирующая функция, характеризующая СЭ. Модель МПС-4 - это структурно-лингвистическая модель представления периода БМС. В модели МПС-5 БМС с ЛСП представлен в виде множества объектов в пространстве параметров. В модели МПС-5 учитываются некоторые особенности МПС-3 (при описании объектов используются параметры кусочно-заданных аппроксимирующих функций) и МПС-4 (БМС рассматривается как множество объектов). На основе рассмотренных в [6] МПС были выделены следующие методы преобразования БС с ЛСП: контурный анализ [9, 10]; преобразование Фурье и вейвлет-преобразование [2 - 4]; структурное преобразование сигнала на основе грамматического разбора [1]; преобразование в фазовое пространство [7, 8]; преобразование в адаптивное пространство параметров аппроксимирующих функций [1]. Таким образом, для проектирования НФ необходимо описать эталон искомого класса структурных элементов БМС с ЛСП.

Цель статьи - исследование способов описания эталона для синтеза функции отклика НФ в обобщенном методе структурной идентификации биомедицинских сигналов с локально сосредоточенными признаками. 
Проектирование нелинейного фильтра. Анализ МПС и методов преобразования БМС с ЛСП позволил выделить ряд однотипных действий при решении задачи СИ. В результате предложена обобщенная схема структурной идентификации БМС с ЛСП на основе НФ (рис. 1).

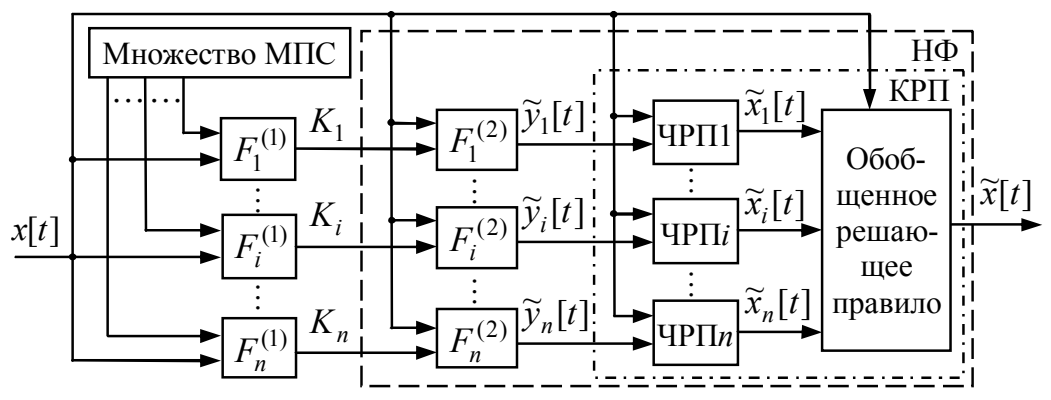

Рис. 1. Обобщенная схема структурной идентификации БС с ЛСП на основе НФ

На вход схемы подается дискретный сигнал $x[t]\left(t=\overline{0 ; T_{s}-1}\right)$, где $T_{s}$ - длина входного сигнала. Преобразование 1-го уровня $F_{i}^{(1)}$ $(i=\overline{1 ; n})$ - это метод преобразования сигнала $x[t]$ на основе МПС, в результате которого получаем кортеж $K_{i}=\left\langle x_{0}[t], \vec{p}_{i}, f_{i}\left(x[t], \vec{p}_{i}\right)\right\rangle$, где $x_{0}[t] \quad\left(t=\overline{0 ; T_{0}-1}\right)$ - эталонный сигнал (эталон СЭ заданного класса); $T_{0}<<T_{s}$ - длина эталона; $\vec{p}_{i}-$ вектор параметров преобразования; $f_{i}\left(x[t], \vec{p}_{i}\right)$ - функция преобразования сигнала $x[t] \quad\left(t=\overline{0 ; T_{s}-1}\right)$ в пределах апертуры для синтеза отклика НФ. Преобразование 2-го уровня $F_{i}^{(2)}$ (см. рис. 1) - это получение новой функции во временной области $\tilde{y}_{i}[t]$, на основании анализа которой выполняется СИ с помощью частного решающего правила (ЧРП). Т.к. адекватность каждой МПС для данного типа СЭ различна, то при проектировании НФ предлагается объединять ЧРП в коллектив решающих правил (КРП). Таким образом, отклик фильтра определяется видом преобразования $F_{i}^{(2)}$ и видом КРП. В свою очередь, вид функции $\tilde{y}_{i}[t]$ в результате преобразования $F_{i}^{(2)}$ напрямую зависит от описания эталона $x_{0}[t]$ искомого класса СЭ.

Способы описания эталона. Как было отмечено выше, в результате преобразования $F_{i}^{(1)}$ получаем кортеж $K_{i}=\left\langle x_{0}[t], \vec{p}_{i}, f_{i}\left(x[t], \vec{p}_{i}\right)\right\rangle$. При 
этом полученная функция преобразования $f_{i}\left(x[t], \vec{p}_{i}\right)$ используется не только для описания сигнала $\omega_{i}^{t}$ в пределах апертуры фильтра, но и для описания эталона $\omega_{i}^{\ni}$ искомого класса СЭ, т.е. $y_{i j}^{\ni}=f_{i}\left(x_{0}[t], \vec{p}_{i}\right)$, $y_{i j}^{t}=f_{i}\left(x[t], \vec{p}_{i}\right)$, где $y_{i j}^{\ni}, y_{i j}^{t}-$ координаты $\omega_{i}^{э}$ и $\omega_{i}^{t}$ соответственно. Рассмотрим способы описания эталона на основе МПС-2 и МПС-5.

Эталонный сигнал на основе МПС-2 с помощью базисных функций $\varphi_{k}[t]$ можно задать следующим образом: $x_{0}[t]=\sum_{k=0}^{T_{0}-1} a_{k} \varphi_{k}[t], t=\overline{0 ; T_{0}-1}$, где $\vec{a}=\left(a_{0}, \ldots, a_{k}, \ldots, a_{T_{0}-1}\right)-$ вектор координат базиса. Если использовать преобразование Фурье, то в качестве базисных функций выступают гармонические функции, если вейвлет-преобразование - то вейвлеты различной формы. В результате эталон описывается вектором $\vec{a}$, а функция перехода от описания эталона во временной области к описанию с помощью вектора коэффициентов $\vec{a}$ - это искомая функция $f_{i}\left(x[t], \vec{p}_{i}\right)$

в кортеже $K_{i}$. Тогда описание эталона $\omega_{i}^{\text {э }}$ на основе МПС-2 имеет следующий вид: $y_{i j}^{\ni}=a_{k}$ для $j=\overline{1, N_{i}}$ и $k \in \mathbf{M}_{k}$, где $N_{i}=\left|\mathbf{M}_{k}\right|-$ количество координат, используемых для описания эталона; $\mathbf{M}_{k} \subseteq\left\{0,1, \ldots, T_{0}-1\right\} \quad-$ множество индексов коэффициентов $a_{k}$, необходимых для описания эталона. При этом вектор параметров $\vec{p}_{i}$ содержит $T_{0}$ и $\mathbf{M}_{k}$. Если все коэффициенты $a_{k} \quad\left(k=\overline{0 ; T_{0}-1}\right)$ используются для описания эталона, то $\mathbf{M}_{k}=\left\{0,1, \ldots, T_{0}-1\right\}$ и $N_{i}=T_{0}$.

Эталонный сигнал $x_{0}[t]$ на основе МПС-5 может быть описан с использованием различных базисных функций (БФ), предложенных в [1]. В качестве БФ могут использоваться разделенные разности, коэффициенты аппроксимирующих полиномов и другие функции. Надо отметить, что в отличие от МПС-2 обратного преобразования не существует. При этом $x_{0}[t]$ разбивается на участки опорными точками таким образом, что каждый полученный фрагмент эталона может быть описан соответствующей БФ. Например, если расставить опорные точки так, как показано на рис. 2, и в качестве БФ использовать разделенную разность 1-го порядка, то описание эталона имеет вид: $y_{i j}^{\ni}=\left(x_{0}\left[t_{k+1}\right]-x_{0}\left[t_{k}\right]\right) /\left(t_{k+1}-t_{k}\right) \quad$ для $j, k=\overline{1, N_{i}}$, где $t_{k}-$ индексы опорных точек. При этом $f_{i}\left(x[t], \vec{p}_{i}\right)$ - это совокупность БФ, а $\vec{p}_{i}$ 
содержит положение опорных точек в апертуре фильтра.

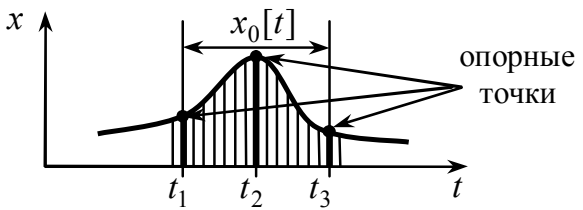

Рис. 2. Пример расстановки опорных точек при задании эталона

Синтез функции отклика нелинейного фильтра. Линейные размеры апертуры $N_{a}$ НФ определяются линейными размерами эталона $x_{0}[t]$ искомого класса СЭ, т.е. $N_{a}=T_{0}$. Т.к. в основу преобразования $F_{i}^{(2)}$ положена идея расчета функции $\widetilde{y}_{i}[t] \in[0 ; 1]$, которая показывает степень схожести эталона $\omega_{i}^{\text {э }}$ с фрагментом сигнала $\omega_{i}^{t}$ в пределах апертуры, то в качестве такой функции предлагается использовать следующую функцию дифференциации расстояний, предложенную в [1]:

$$
\tilde{y}_{i}[t]=d^{(\alpha)}\left(\omega_{i}^{\ni}, \omega_{i}^{t}\right)=\sqrt{\alpha \sum_{j=1}^{N_{i}}\left(y_{i j}^{\ni}-y_{i j}^{t}\right)^{2} /\left(1+\alpha \sum_{j=1}^{N_{i}}\left(y_{i j}^{\ni}-y_{i j}^{t}\right)^{2}\right)},
$$

где $y_{i j}^{\ni}, y_{i j}^{t}$ - координаты эталона $\omega_{i}^{\ni}$ и фрагмента сигнала в пределах апертуры $\omega_{i}^{t}$ соответственно; $\alpha \in(0 ; 1]-$ коэффициент, отражающий чувствительность к изменениям СИ одного класса за счет наложения помех и вариации параметров.

На основании функции $\tilde{y}_{i}[t]$ выполняется структурная идентификация с помощью порогового решающего правила:

$$
\tilde{x}_{i}(t)= \begin{cases}x[t] \forall t \in\left[t_{0 j} ; t_{0 j}+T_{0}\right], & \text { если } \tilde{y}_{i}\left[t_{0 j}\right]<P d ; \\ \text { const } & \text { в остальных случаях, }\end{cases}
$$

где $t_{0 j}$ - точка локального минимума функции $\tilde{y}_{i}[t]$ такая, что $y_{i}\left[t_{0 j}\right] \leq \tilde{y}_{i}[t] \quad \forall t \in \dot{\mathbf{M}}\left(t_{0 j}\right) ; \quad \dot{\mathbf{M}}\left(t_{0 j}\right)=\mathbf{M}\left(t_{0 j}\right) \backslash\left\{t_{0 j}\right\} \quad-\quad$ проколотая окрестность точки $t_{0 i} ; \mathbf{M}\left(t_{0 j}\right)$ - окрестность точки $t_{0 j} ; P d$ - пороговое значение.

Выводы. В данной работе рассмотрены способы описания эталона искомого класса СЭ на основе различных МПС в обобщенном методе структурной идентификации БМС с ЛСП, а также синтез функции отклика проектируемого НФ. Дальнейшие исследования направлены на экспериментальную проверку эффективности различных способов 


\section{описания эталона и исследование методов синтеза КРП.}

Список литературы: 1. Філатова Г.С. Структурна ідентифікація сигналів у кардіологічних системах: дис. канд. техн. наук: спец. 05.11.17 / Філатова Ганна Євгенівна. - Харків, 2002. 177 с. 2. Айфичер Э. Цифровая обработка сигналов: Практический поход / Айфичер Э., Джервис Б. - М.: Издательский дом «Вильямс», 2004. - 992 с. 3. Сергиенко А.Б. Цифровая обработка сигналов: Учебное пособие. Второе издание. / Сергиенко А.Б. - СПб.: Питер, 2006. -752 с. 4. Оппенгейм А. Цифровая обработка сигналов / Оппенгейм А., Шафер Р. - М.: "Техносфера", 2007. - 856 с. 5. Татарский Б.Г. Многофункциональные радиолокационные системы. Учебное пособие для вузов / Татарский Б.Г., Дудник П.И., Ильчук А.Р. - М.: Дрофа, 2007. -283 с. 6. Філатова Г.С. Нелинейная фильтрация биомедицинских сигналов с локально сосредоточенными признаками в задаче структурной идентификации / Філатова Г.Є. // Вісник НТУ "ХПІ". - Харків: НТУ "ХПІ". - 2011. - № 17. - С. 168-174. 7. Файнзільберг Л.С. Методи та інструментальні засоби оцінювання стану об'єктів за сигналами 3 локально зосередженими ознаками: автореф. дис. на здобуття наук. ступеня доктора техн. наук: спец. 05.13.06 / Файнзільберг Л.С. - К., 2004. - 35 с. 8. Файнзильберг Л.С. ФАЗАГРАФ ${ }^{\circledR}$ - эффективная информационная технология обработки ЭКГ в задаче скрининга ишемической болезни сердца / Файнзильберг Л.С. // Клиническая информатика и телемедицина. - 2010. - Т. 6. - Вып. 7. - С. 22-30. 9. Абакумов В.Г. Біомедичні сигнали. Генезис, обробка, моніторинг. Навчальний посібник / Абакумов В.Г., Рибін О.І., Сватоши Й. - К.: Нора-прінт, 2001. - 516 с. 10. Вычислительные системы и автоматическая диагностика заболеваний сердца / Под ред. Ц. Касереса, Л. Дрейфуса. - М.: Мир, 1974. - 504 с.

УДК 61:007+004.932.72

Опис еталону для синтезу функції відгуку нелінійного фільтру у задачі структурної ідентифікації біомедичних сигналів с локально зосередженими ознаками / Поворознюк А.І., Філатова Г.Є. // Вісник НТУ "ХПІ". Серія: Інформатика та моделювання. - Харків: НТУ "ХПІ". - 2012 - № 38. - С. 136 - 141.

В роботі розглядається задача структурної ідентифікації біомедичних сигналів 3 локально зосередженими ознаками за допомогою цифрового нелінійного фільтру, а також способи опису еталона шуканого класу структурних елементів на основі моделей корисного сигналу для синтезу функції відгуку проектованого фільтру. Іл.: 2. Бібліогр.: 10 назв.

Ключові слова: структурна ідентифікація, біомедичний сигнал, локально зосереджені ознаки, цифровий нелінійний фільтр, еталон, структурний елемент.

UDC 61:007+004.932.72

The description of the standard template, used for the non-linear filter response function synthesis, in the problem of structure identification of biomedical signals with locally focused characteristics / Povoroznyuk A.I., Filatova A.E. // Herald of the National Technical University "KhPI". Subject issue: Information Science and Modeling. - Kharkov: NTU "KhPI". - 2012. - №. 38. - P. 136 - 141.

This work is devoted to the problem of structural identification of biomedical signals with locally focused characteristics using a digital non-linear filter. The methods, used to specify the standard template for the required class of structural elements, based on the useful signal models, for the projected filter response function synthesis, are overviewed too. Figs: 2. Refs: 10 titles.

Keywords: structural identification, biomedical signal, locally focused features, digital nonlinear filter, a standard template, a structural element.

Поступила в редакичию 12.04.2012 